\title{
Problem of the pedestrian route system in the center of Saint-Petersburg
}

\author{
Leonid Lavrov ${ }^{1, *}$, and Andrei Surovenkov ${ }^{1}$ \\ ${ }^{1}$ Saint Petersburg State University of Architecture and Civil Engineering
}

\begin{abstract}
Existing proposals for expanding pedestrian routes in the central part of St. Petersburg are analyzed and critically assessed, based on existing regulatory documents. On the basis of quantitative indicators and a comparative analysis of the central regions of European cities, the idea of the central regions of St. Petersburg as a territory with dense buildings, small quarters with a dense network of intra-quarter communication routes is questioned. Attention is paid to the legal problems of developing the system of intra-quarter communication routes in the central part of St. Petersburg. Based on European experience, a number of possible solutions are proposed.
\end{abstract}

\section{Introduction}

Recently, a number of strategies and programs on improving the comfort of the urban environment, including the development of pedestrian areas, improving the efficiency and safety of traffic, have been developed for the historical center of St. Petersburg. The main documents are the Decree of the Government of St. Petersburg "On the transport strategy of St. Petersburg until 2025" [1] and "On the concept of development of pedestrian areas of the historical center of St. Petersburg" [2].

According to TSN 30-306-2002 - the norms that determine the policy of reconstruction and development of the central part of St. Petersburg, the historical part of the city "is characterized by a high density of street-road network, small quarter sizes ...", "... the compactness of intra-quarter spaces and the development of intra-quarter pedestrian routes" [3].

Despite this statement, it is necessary to note the fact that the network of intra-quarter pedestrian traffic in the central part of St. Petersburg is far from its European counterparts in terms of development, and the number of spaces accessible to pedestrians is rapidly decreasing [4]. This is also evidenced by the fact that "over eight thousand apartment buildings have an encumbrance in the form of "zones for pedestrian and car passage"- the city authorities are trying to somehow provide free access to the courtyards" [5].

The "Concept for the development of pedestrian areas of the historical center of St. Petersburg" developed by the Government of St. Petersburg highlights the problem of underdevelopment of pedestrian routes in the historical center of the city: "The specific planning structure of the intra-district highways of the historical center of St. Petersburg,

* Corresponding author: leonid.lavrov@gmail.com 
associated with passage under tight construction conditions, the presence of a large number of regulated intersections, determines a high degree of movement along these streets and uncomfortable conditions for pedestrian traffic, which for the most part move along narrow sidewalks that are actually not separated from the roadway" [2].

As the main solution to increase the density of the pedestrian network, it is proposed to expand the area of pedestrian streets, increase the number of comfortable pedestrian traffic areas (areas within the boundaries of which the advantage of safe and convenient traffic for pedestrians is provided) [2] by, among other things, reducing the width of the roadway.

In the concept, "a large number of regulated intersections" is recorded as one of the reasons for the uncomfortable movement of pedestrians in the city center. A large number of intersections suggests a greater connectivity of travel routes, as well as a varied choice of routes, including pedestrian routes [6], which, if we share the opinion expressed in the concept, would only improve the situation with transport and pedestrian traffic in the city. But this point of view, which is inextricably linked with the view officially recognized in TSN 30-306-2002 that the historical part of the city "is characterized by a high density of the road network, small quarter sizes" [3], is not shared by all researchers studying the transport network of the historical part St. Petersburg [7, p. 42-47].

\section{Methods and Results}

Let's analyze the density of buildings in the central parts of St. Petersburg (for example, in the eastern part of Vasilievsky Island) and the central regions of European cities. At the initial stage, it is proposed to graphically compare the development of the central part of St. Petersburg and European million-plus cities with the number of inhabitants close to St. Petersburg. According to the data of 2017-2019, the closest cities in terms of population to St. Petersburg are Istanbul (9 772961 people), London (8 787892 people), Berlin (3 601 131 people), Madrid (3 223334 people), Rome (2 872800 people), Kiev (2 950676 people), Paris (2 140526 people) [8].

Let's combine the outlines of the quarters of St. Petersburg with satellite imagery of European cities (Fig. 1).

As expected, even the visually historical center of St. Petersburg is significantly different from its "colleagues" from Europe - the size of the blocks in St. Petersburg is significantly larger than in European counterparts. Such indicators as the density of the road network and the number of intersections, including regulated ones, on the contrary, are higher. Pedestrians in the central part of European cities have more options for choosing travel routes, and their path "from point A to point B" is shorter than in St. Petersburg.

For a more accurate analysis, it is proposed to compare the largest cities in Europe by digital indicators. A number of official sources published data on the density of the road network in major cities around the world. In particular, the statistics were published in the report of the Moscow Government "Current state of the main street-road network" [9] and "Strategy for the development of the transport system of St. Petersburg and the Leningrad Region for the period until 2030" [10] developed by Transport Integration LLC. It is reported that the average indicator for cities is $(\mathrm{km} / \mathrm{sq}$. $\mathrm{km})$ : Moscow - 4.4, London - 9.3, New York - 12.4, Paris - 15.0, Berlin-8.6. [9]. In St. Petersburg, there is an average of 2.4 $\mathrm{km}$ of roads per $1 \mathrm{sq}$. $\mathrm{km}$ [10], which makes it an outsider in this list. Even in the city center, the street density is up to $11 \mathrm{~km}$ per $1 \mathrm{sq} . \mathrm{km}$ [8] (according to other sources, up to $5-6 \mathrm{~km}$ ) [10], in the historical quarters of Vasilievsky Island $-7.6 \mathrm{~km} / \mathrm{sq} . \mathrm{km}$, which is comparable with the sleeping areas of Moscow, where there are $6-8 \mathrm{~km}$ of streets per $1 \mathrm{sq}$. $\mathrm{km}$. of development [11]. 

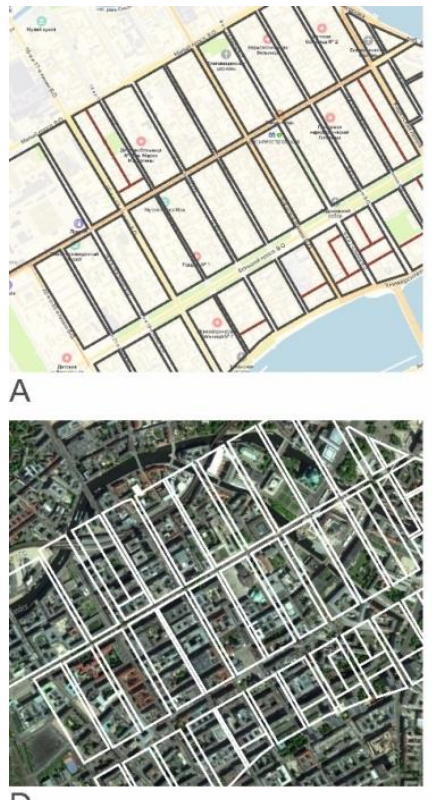

D

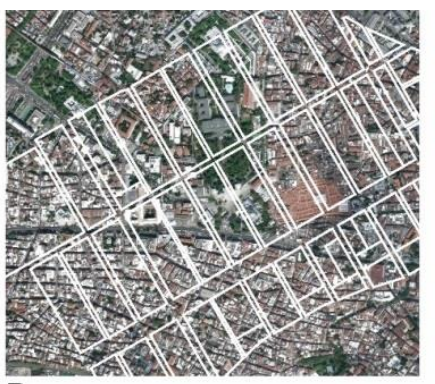

B

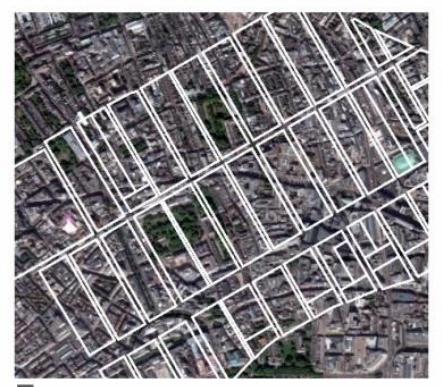

E

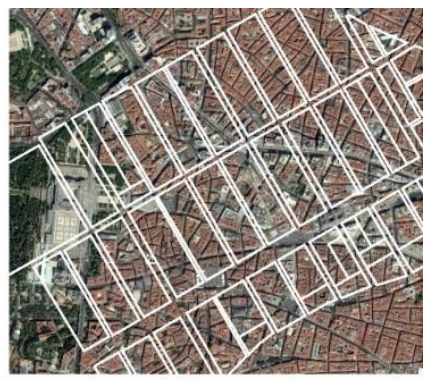

C

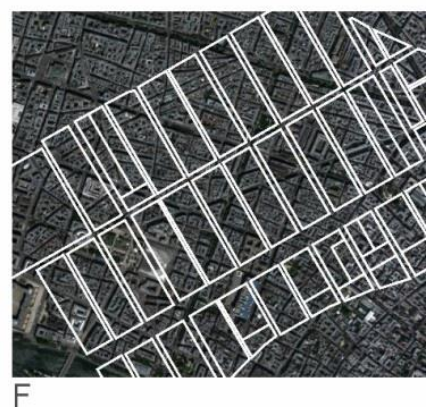

A - scheme of the eastern part of Vasilievsky Island with the overall dimensions of the quarters (intra-quarter driveways are marked in red), B - the overall scheme of the quarters of Vasilievsky Island against the background of a satellite image of the center of the western part of Istanbul, C scheme of the quarters of Vasilievsky Island against the background of the center of Madrid, D scheme of the quarters of Vasilievsky Island against the background of the center of Berlin, E scheme of the quarters of Vasilievsky Island against the background of the center of London, F scheme of the quarters of Vasilievsky Island against the background of the center of Paris

Fig. 1. Comparison of urban pattern of European cities:

According to another important indicator - the relative indicator of the area of the road network per one inhabitant (m2/person), St. Petersburg is also much inferior to other large cities. In our city, this indicator is $10 \mathrm{~m} 2$ /person, in Moscow - 12, in New York - 32, Los Angeles - 105 [12].

Based on the information provided, it can be argued that both the "On transport strategy of St. Petersburg until 2025" and the "Concept for the development of pedestrian areas of the historic center of St. Petersburg" do not take into account the limited territorial resource. The proposal to redistribute the territories of the existing street-road network ("reconstruction of sidewalks in accordance with the real intensity of pedestrian flows, development of areas of increased comfort for pedestrians and the creation of pedestrian zones" [13]) cannot be implemented in large volumes without worsening the already problematic situation with transport.

The size of the quarters of the historical center, far exceeding the quarters of the central zones of European cities, also does not contribute to a comfortable and safe movement. According to studies, long quarters are unsafe for pedestrians. The most comfortable recommended quarter length, which will increase the level of convenience of walking - 75150 meters [6]. With the increased length of quarters (from 200 meters or more), additional measures are necessary to ensure connectivity of the development zones separated by streets for pedestrians [6]. The compact size of the neighborhoods or their permeability, providing a developed communication routes network in any direction, allows reducing the distance from home to the metro, shop, etc., which allows more often choosing a walk and reduces the dependence on a personal car and public transport [6]. 
The large number of intersections in the city center, indicated in the "Concept for the development of pedestrian areas of the historic center of St. Petersburg", is not an obstacle to creating a comfortable environment for pedestrians: "small blocks in the center of Shanghai provide a more suitable street network for pedestrians, as opposed to long ones, in which cars develop high speed, and pedestrians are often forced to cross the road in the wrong places with danger to life" [6]. It should also be noted that the number of intersections depends on the saturation of the street-road network, the density of which is low in St. Petersburg.

In the Middle Ages, the quarter in both European and Russian cities was not only a territorial, but also a social unit - a collective of neighbors who jointly performed urban duties [14]. Social communications provided developed intra-quarter communications "the quarter itself is a connected space - namely, a multitude of elements (spaces, sections, structures) that are continuously interconnected by certain physical characteristics: a single constructive system, circulating and engineering communications, types of zones of a person's stay" [15]. The system of quarters that arose in the core of the historical center of St. Petersburg almost does not have such intra-quarter communications. Structural and planning elements that determine the nature of intra-quarter communications are revealed in Figure 3. The yellow lines indicate the passage through the front buildings ("arches"), the red lines show the communication lines between the individual yards. The planning options for Vasilievsky Island, which developed the concept of D. Trezzini, included a system of intra-quarter lanes [16]. From the 1740s, another structure of the quarter became dominant on the Central and Admiralty side, with two-row cutting of land plots for fenced property plots that had no other connections than the street. In the densely built-up quarter, there was no space for intra-quarter communication routes [17, p. 15-20].

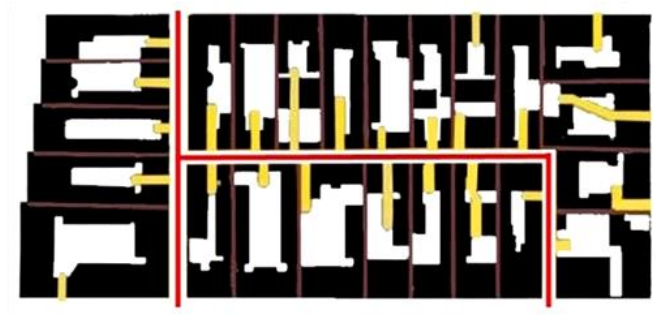

A 7th line of Vasilievsky island

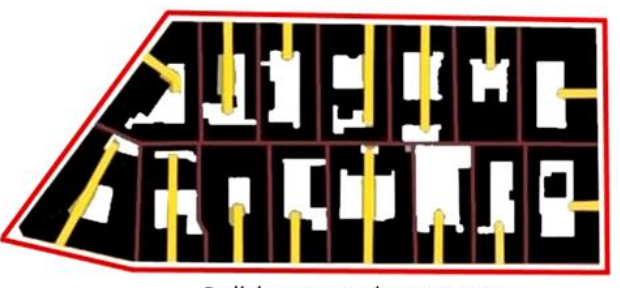

Bol'shaya morskaya street

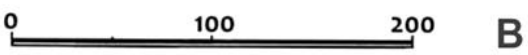

A - sample of the 1720-30s (D. Trezzini, 7th line of Vasilievsky Island),

B - version of the 1740-1840s (version of the Commission of the building, B. Morskaya street)

Fig. 2. Features of pedestrian communication in the characteristic St. Petersburg neighborhoods.

With the compaction of site development, erection and superstructure of courtyard outbuildings, "architecturally separate intra-quarter territories became more and more open in public, social relation" [18]. Due to the lack of walking routes in the interior spaces, the quarters have become absolutely "impenetrable". Nowadays, the process of removing intraquarter passages from the city-wide communications system is almost complete.

The development of such quarters is not characterized by the "development of intraquarter pedestrian routes", as stated in regional standards [3]. 


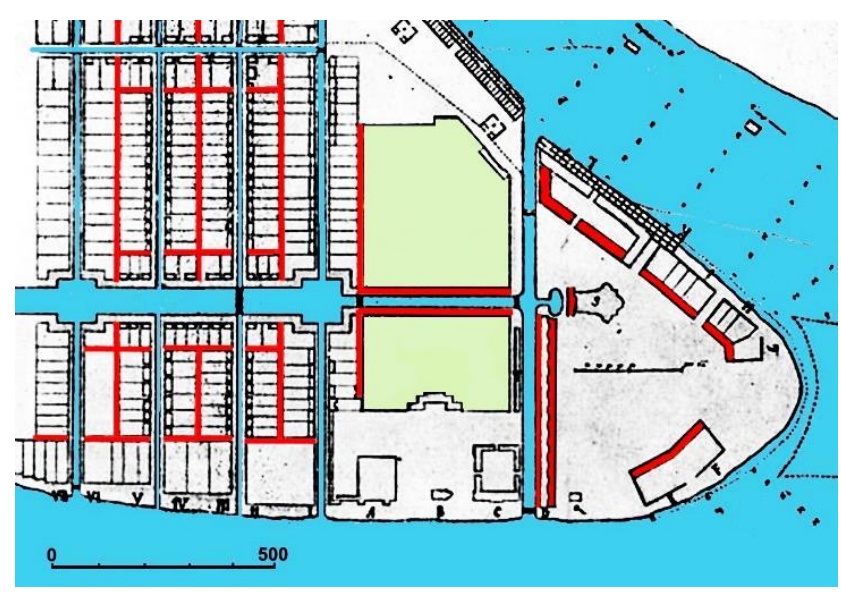

Fig. 3. The concept of Domenico Trezzini on the planning and development of the Spit of Vasilievsky Island in St. Petersburg.

The concept for the development of pedestrian areas of the historical center of St. Petersburg, in addition to the option to redistribute the territories of the existing street-road network, offers "the creation of new convenient and safe pedestrian connections between existing pedestrian streets and streets with slow traffic" [10].

To identify a reserve not connected with the street-road network for expanding the network of pedestrian communications, we will analyze the main elements of the city pedestrian networks of St. Petersburg.

The main resources of pedestrian routes in the center of St. Petersburg are sidewalks, which are inextricably linked with the roadway of the street-road network. Given the density of the street-road network in the center of St. Petersburg, it is obvious that their resource is limited. In an almost exhaustive list of other components of the pedestrian routes of the central regions, we can note:

- official transit passages through the territory of the quarters ("Yards of the chapel", passage to the Neva along the recently opened Shuvalovsky passage through the Hermitage complex, alley in block 130 from Vosstaniya Street to Mayakovsky Street)

- intra-quarter lanes in the Vasileostrovsky district, (Repin St. and Inostranny, Academichesky, Bugsky, Dnepropetrovsky, Tuchkov lanes, Donskaya St., Nemansky lane) [16].

- the number of passage yards is constantly decreasing due to closing entrances.

The last category of city-wide pedestrian communication routes, as amended by TSN 30-306-2002, "transit passages through the quarter", is one of the reserves for creating a developed network of pedestrian communication routes in the center of St. Petersburg [3].

To assess the possibility of creating such a network, let us turn to European experience. It is necessary to distinguish two main types of intra-quarter passages - performing exclusively a transit function and being multifunctional, in which, in addition to transit, there is a developed social component - cafes, restaurants, shops, etc. are located along the entire passage, thus, the passages turn into a kind of shopping centers, closely integrated into the city communications system. 

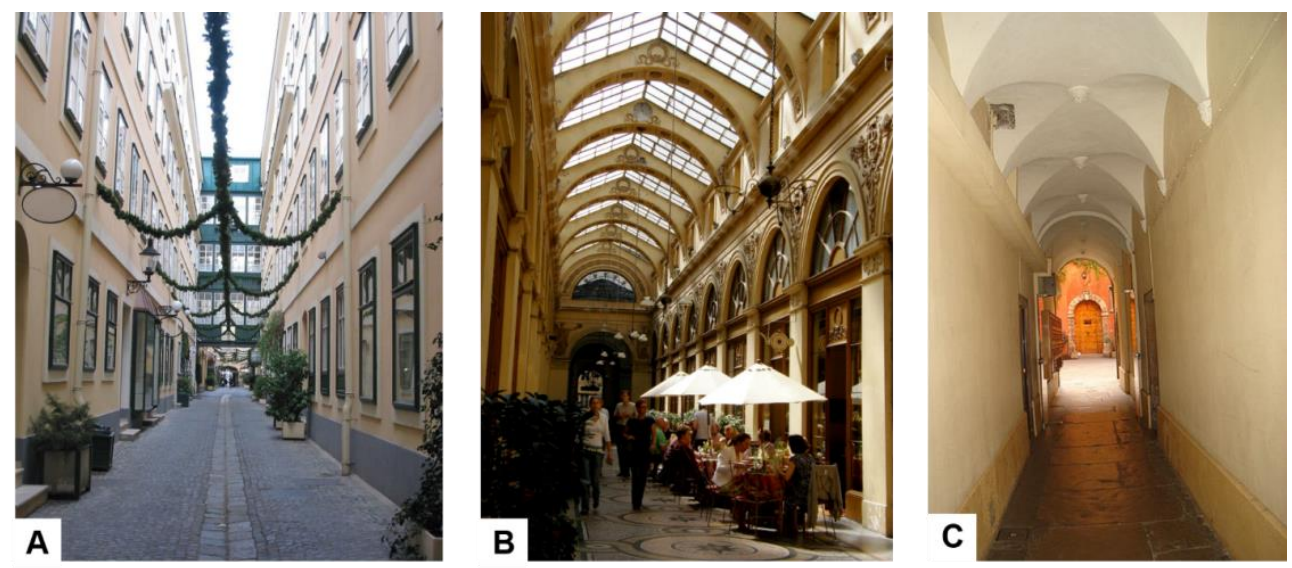

Fig. 4. A - Der Sünnhof, Vienna, B - Galerie Vivienne, Paris, C - Traboule de la Tour Rose, Lyon.

Multifunctional transit passages:

- about 700 passage yards with the local name Durchhäuser are part of Vienna's pedestrian network [19]. By their main characteristics, they can be compared with similar passages in St. Petersburg. But unlike open Petersburg walkways, intra-quarter communications in Vienna are filled with elements of a social service system, often leading to courtyards (Pawlatschen) with cafes and restaurants [20].

- in addition to the developed street system, in the $1850 \mathrm{~s}$, there were about 150 covered walkways in Paris [21]. Currently, only 17 intra-quarter transits remain in the historical center of the city [22]. These capital structures are called "passages", as well as pedestrian routes that arose in the blocks along with their development. Unlike the "pedestrian routes", multifunctional covered walkways began to appear in Paris in the 19th century and became widespread until the mid-19th century, which was interrupted by the reforms of Baron Osman [21]. Only part of the passages has a transit function.

- at the beginning of the 19th century, in the already developed buildings in the center of Milan, business began to develop intra-quarter spaces. After the construction of the first shopping gallery - Galleria De Cristoforis [23], a developed network of passages with a system of commercial and business facilities appeared in the central part of the city.

- the system of shopping galleries arose and began to expand in the center of Hamburg in the context of the existing buildings also at the beginning of the 19th century. Before the Second World War, "almost the entire central part of the city was built up with passages so that it was possible to calmly make all kinds of purchases without getting wet in the rain" [24].

Nowadays, such pedestrian communication routes, having the appearance of public corridors, are characteristic of business and commercial areas with high building density of neighborhoods. Usually they are called "passages" or "galleries", and they are perceived as an integral part of the pedestrian zones of the center [16].

Transit passages:

- 500 narrow pedestrian corridors laid through the quarters of the old part of Lyon, occupying 500 hectares and having 230 streets [25]. In Lyon they are called "traboule" [26], in Venice - "sotoportego" [27]. Similar passages that arose in a large number of medieval cities and at first performed exclusively a communication function began to appear simultaneously with the development of quarterly development.

In the process of development and growth of cities, problems arose between the residents of the quarter, transit visitors and city authorities. It was beneficial for the city authorities, as well as for many city dwellers, to keep intra-quarter routes open to facilitate 
movement around the city. Residents of the blocks through which transit routes pass often were unhappy with the constant presence of noisy companies from other areas of the city on private territory.

Nowadays, to resolve such contradictions, there are two most common solutions:

In the case of transit spaces where business is not represented, city authorities interested in preserving these pedestrian paths usually enter into agreements with residents - in Lyon, some intra-quarter passages through buildings ("traboules") belong to the city, others are private property. The city authorities compensate for part of the costs of lighting, cleaning and repair of the traboules. For this, owners provide unhindered access to the traboules at the agreed time (usually from 7:00 to 19:00 or until 20:00) [28]. Paris passages having only a transit function are usually open only from 8-30 in the morning until 20-30 in the evening, the rest of the time their entrances and exits are locked. Many are closed on Sunday [29].

In multifunctional transit spaces with a system of commercial and business facilities, there are various agreements between residents and business residents. These agreements relate to the joint maintenance of intra-quarter spaces, control over them, and also regulate the access time. In many Viennese Durchhäuser, access to the courtyard is closed late in the evening to protect the night's rest.

Many intra-quarter passages, including some galleries in Milan, passages in Paris and Hamburg, despite the fact that they are laid in the existing buildings, do not have any connections with intra-quarter living spaces (Fig. 5).
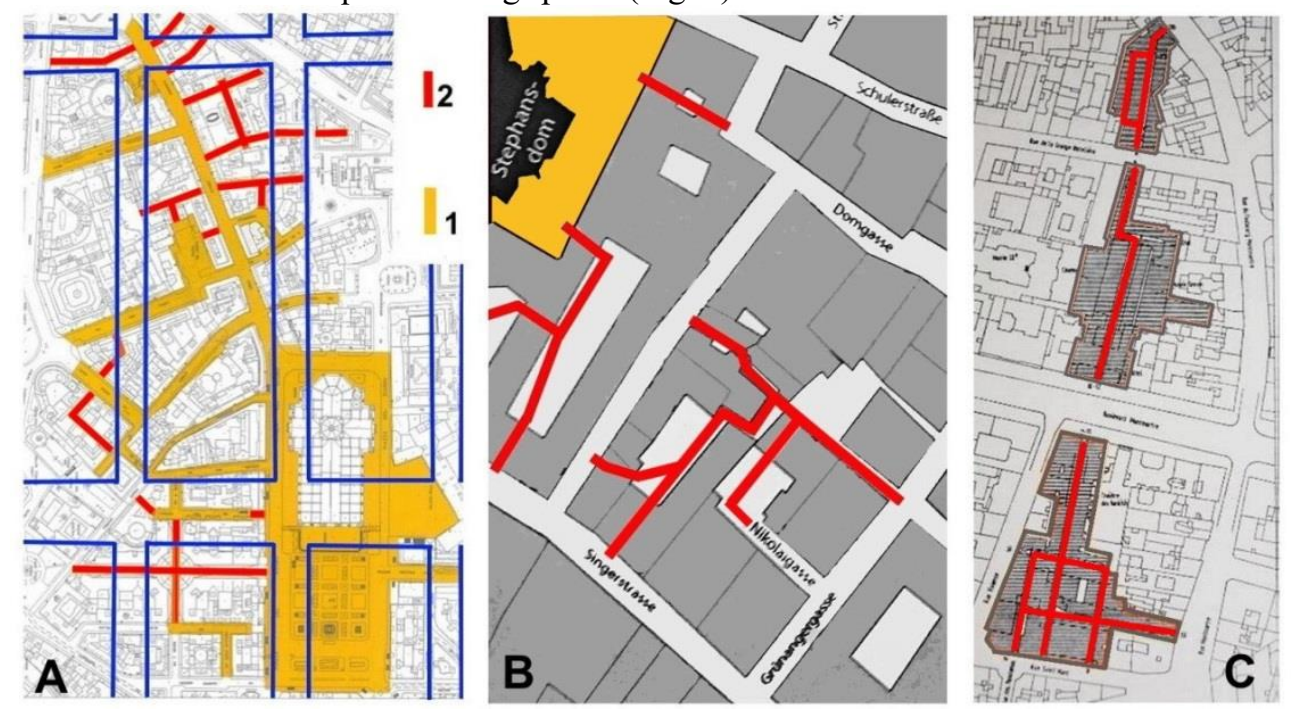

Fig. 5. Pedestrian communication routes network in public trade zones (pedestrian streets and squares are highlighted in yellow, intra-quarter passages - in red): A- Milan, BVienna, S - Paris

Prospects for improving pedestrian traffic in the historical center of St. Petersburg.

Studies conducted at Saint Petersburg State University of Architecture and Civil Engineering led to the conclusion that it is advisable to separate transport and pedestrian routes in the center of St. Petersburg [30]. The status of the UNESCO World Heritage Site "The Historical Center of St. Petersburg and Associated Groups of Monuments" does not allow changing the planning structure (passage network, laying out of quarters) [31], but does not exclude the possibility of using intra-quarter resources - as is done in Vienna, Lyon, Milan and hundreds of other European cities. 
In recent years, urban development projects, for the most part, have ignored the possibility of increasing the pedestrian "permeability" of the center through intra-quarter communications:

- only in the "Concept of pedestrian spaces and continuous pedestrian routes" developed by the Committee for City Planning and Architecture in 2017 [32], the idea of laying a pedestrian corridor through block 2006 on Vasilievsky Island, which stands out for its area (32 hectares) and is impenetrable for pedestrians, which was forgotten for a long time, is indicated. Since Peter's times, this spot of the former huge estate of Menshikov cuts off the residential area of the island from the Spit ensemble. In 1720, D. Trezzini planned to extend the Bolshoi Avenue through the territory of the estate. The route planned by him existed in the general plan of 1966, but disappeared in modern urban planning drawings [16].

- in the early 2000s, a radical reconstruction of the "Grand quarter" (Paradny Kvartal), where the Preobrazhensky regiment was previously quartered, was made. On a territory of 16 hectares, the development, utilities and landscaping have been completely updated. Business and social services were located in the quarter open to pedestrians, but the decision to place the entire territory of the quarter on a single stylobate almost killed the entire transit through the quarter.

- in the "Concept for the development of pedestrian areas of the historical center of St. Petersburg", the option of using intra-quarter spaces is practically not considered - this solution is proposed only for two of the 14 territories identified by the Concept that make up the historical center of St. Petersburg.

- in the schemes of the section "Proposals for pedestrian spaces and continuous pedestrian routes" of the "Concepts of pedestrian spaces and continuous pedestrian routes", there are almost no proposals for the use of intra-quarter communication spaces. In most cases, the option of landscaping yards with the possibility of access to them without the possibility of transit was proposed (Fig. 5).

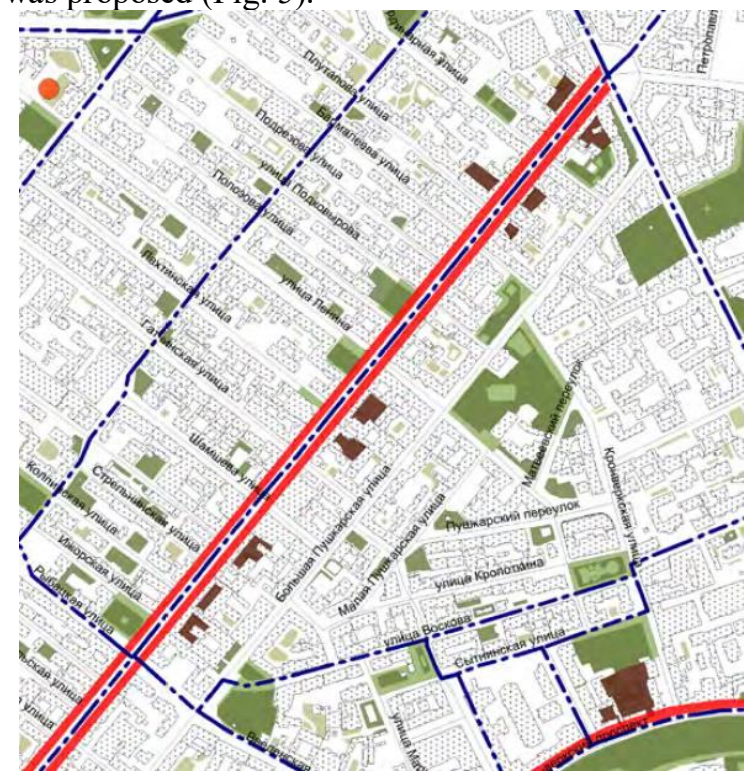

Fig. 6. Petrograd district. Proposals for pedestrian spaces and continuous pedestrian routes. The concept of pedestrian spaces and continuous pedestrian routes. [32].

Urban planning activity regarding the return of intra-quarter passages to the citywide pedestrian communications system is hindered by defects in the Russian land use system that have developed as a result of housing and communal services reform. Residents who 
received apartment ownership as a result of gratuitous privatization still do not bear the full tax burden on their property. Payment of housing and communal services does not occur in full - part of these costs is compensated by the state, which also has its negative consequences. In the transition economy, in the end, it is necessary to balance the prices on the housing and communal services market with the incomes of property owners and tenants [33]. This imbalance creates many problems, including in the use of intra-quarter spaces. Due to the fact that, according to subparagraph 6 of paragraph 2 of Article 389 of the Tax Code, land plots that are part of the common property of an apartment building are not recognized as a tax on land [34]. Residents who do not pay for the territory of intraquarter passages block the entrance to the courtyards and seize the courtyard territory, and in some cases, the territory of green spaces, from the system of citywide pedestrian areas.
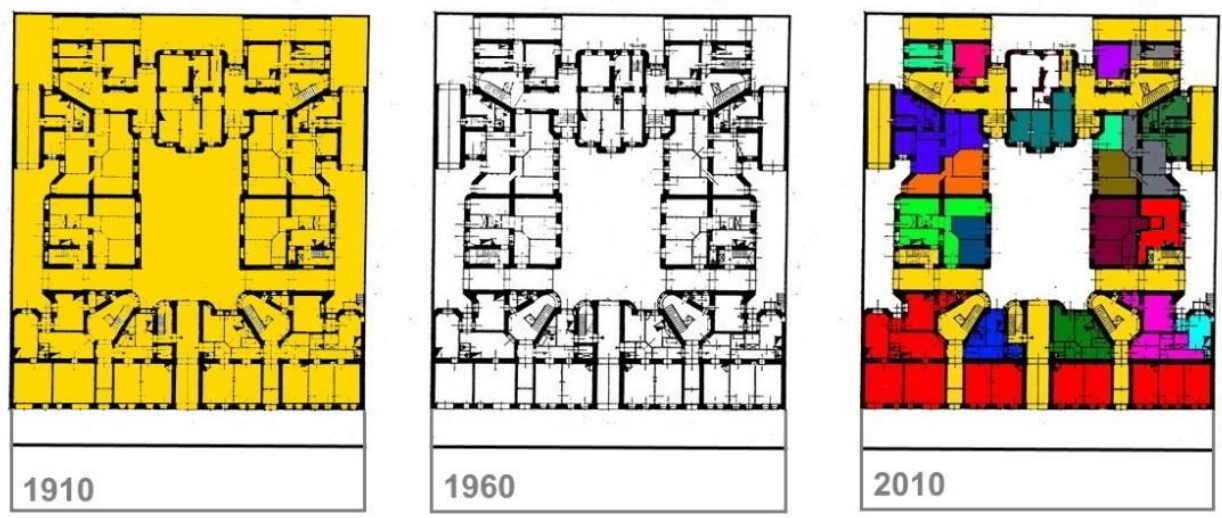

Fig. 7. The evolution of property rights. Tenement building of the Krieger association, Novgorodskaya, 12, St. Petersburg.

The city's authorities are trying to fight this trend - as indicated at the beginning of the paper, about 8,000 courtyards in the city center are encumbered with "zones for pedestrian and car passage". But local residents successfully fight with this burden, as illegal and absent in the Land and Civil Codes [35]. Nowadays, attempts are being made to establish easements for the courtyard territories, which is also fraught with a lot of difficulties [36], including the procedure for establishing payment for easements to the owners of the territory, as well as passing public hearings.

The above problem concerns the courtyards owned by the residents, but, with rare exceptions, the yards are a city-wide territory [35]. Despite the lack of rights to the plot, residents, in fact, committing an administrative violation, close these yards.

In both cases, we can recommend the European experience, and, in particular, the relationship of the authorities, business and the city in Lyon and Vienna. The development of agreements on joint maintenance and cleaning of the territory, incurring the costs of its operation in exchange for an open passage through the courtyard territory and the smooth operation of the business in the intra-quarter spaces in the daytime can be a compromise that will benefit all parties.

\section{Conclusion}

Quarters, originally built with the absence of common communication spaces, and also lost them during the development process, can be transformed taking into account the experience of creating multi-functional spaces described in the paper (for example, Hamburg, Paris and Milan), both isolated from the courtyard spaces and connected with 
them. Within the framework of this solution, pedestrian corridors can be laid through the side courtyard outbuildings to ensure connectivity of the courtyard spaces. Moreover, on the lower floors of the outbuildings to which access will be provided, the placement of business residents seems to be optimal, since this premises, for the most part, cannot be used as residential premises due to poor insolation [37].

\section{References}

1. On the Transport Strategy of St. Petersburg until 2025 (as amended on June 14, 2017) http://docs.cntd.ru/document/891854661

2. On the concept of development of pedestrian areas of the historical center of St. Petersburg http://pravo.gov.ru/proxy/ips/?docbody $=\&$ prevDoc $=131045917 \&$ backlink $=1 \& \& n d=13$ 1026851

3. TSN 30-306-2002 St. Petersburg (Territorial Building Norms "Reconstruction and development of historically developed areas of St. Petersburg")

4. Through seventeen lines: the St. Petersburg architect made a map of the passage yards of Vasilievsky Island https://www.spb.kp.ru/daily/26828/3868672/

5. A "courtyard" easement is proposed to be introduced in St. Petersburg. https://news.rambler.ru/other/42400498-v-peterburge-hotyat-vvesti-dvorovyy-servitut/

6. Archi-text: designing safe cities. https://xn--80akijuiemcz7e.xn--p1ai/blog/arhi-tekstproektirovanie-bezopasnyh-gorodov

7. V.K. Linov Bulletin of civil engineers 4(33) (2012)

8. Wikipedia. Cities of Europe with a population of more than 500 thousand people https://ru.wikipedia.org/wiki/\%D0\%93\%D0\%BE\%D1\%80\%D0\%BE\%D0\%B4\%D0\% B0_\%D0\%95\%D0\%B2\%D1\%80\%D0\%BE\%D0\%BF\%D1\%8B_\%D1\%81_\%D0\%BD $\% \overline{\mathrm{D}} \% \% \mathrm{~B} 0 \% \mathrm{D} 1 \% 81 \% \mathrm{D} 0 \% \mathrm{~B} 5 \% \mathrm{D} 0 \% \mathrm{BB} \% \mathrm{D} 0 \% \mathrm{~B} 5 \% \mathrm{D} 0 \% \mathrm{BD} \% \mathrm{D} 0 \% \mathrm{~B} 8 \% \mathrm{D} 0 \% \mathrm{~B} 5 \% \mathrm{D} 0$ $\% \mathrm{BC} \% \mathrm{D} 0 \% \mathrm{~B} 1 \% \mathrm{D} 0 \% \mathrm{BE} \% \mathrm{D} 0 \% \mathrm{BB} \% \mathrm{D} 0 \% \mathrm{~B} 5 \% \mathrm{D} 0 \% \mathrm{~B} 5 \quad 500 \% \mathrm{D} 1 \% 82 \% \mathrm{D} 1 \% 8 \mathrm{~B} \% \mathrm{D}$ $1 \% 81 \% \mathrm{D} 1 \% 8 \mathrm{~F} \% \mathrm{D} 1 \% 87 \ldots \mathrm{D} 1 \% 87 \% \mathrm{D} 0 \% \mathrm{~B} 5 \% \mathrm{D} 0 \% \mathrm{BB} \% \mathrm{D} 0 \% \mathrm{BE} \% \mathrm{D} 0 \% \mathrm{~B} 2 \% \mathrm{D} 0 \% \mathrm{~B} 5$ $\% \mathrm{D} 0 \% \mathrm{BA}$

9. The current state of the main street-road network. https://docplayer.ru/42528736Sovremennoe-sostoyanie-magistralnoy-ulichno-dorozhnoy-seti.html

10. Strategies for the development of the transport system of St. Petersburg and the Leningrad Region for the period until 2030. http://spbtrd.ru/program-development/

11. Priority - quarterly development https://archi.ru/russia/50044/prioritet-kvartalnoizastroike

12. Urban street-road network - Studme.org https://studme.org/96669/logistika/ulichnodorozhnaya_set_gorodov

13. On the transport strategy of St. Petersburg until 2025 http://pravo.gov.ru/proxy/ips/?docbody $=\& n d=131043008 \& \mathrm{rdk}=0$ (reference dates: 15.07.2019, 09.09.2019)

14. V.L. Glazychev Urban Studies (Moscow, Europe, 2008)

15. A. P. Kudryavtsev, M. V. Shubenkov, Structural features of architectural shaping (Moscow, Architecture-S, 2006)

16. L.P. Lavrov, A.V. Surovenkov, Collection of materials of the V All-Russian scientificpractical conference "MODERN PROBLEMS OF HISTORY AND THEORY OF ARCHITECTURE”, 43-51 (2019) 
17. S.V. Sementsov, Bulletin of civil engineers 2 (7) (2006)

18. B.M. Kirikov. Architecture of Petersburg at the end of the 19th - beginning of the 20th century. Eclecticism. Fashionable. Neoclassicism, 47-58 (St. Petersburg, Kolo, 2014)

19. Abkürzungen für Fußgänger: Wien schildert "Durchhäuser" aus https://derstandard.at/2000073942894/Abkuerzungen-fuer-Fussgaenger-Wien-schildertDurchhaeuser-aus

20. Die Wiener Durchhäuser. https://www.timetravel-vienna.at/news/details/die-wienerdurchhaeuser/

21. The covered passageways of Paris http://www.parisparcours.com/itinerary/25/thecovered-passageways-of-paris)

22. Paris passages. https://frenchparis.ru/passage-des-panoramas/

23. Wikipedia. Galleria De Cristoforis. https://it.wikipedia.org/wiki/Galleria_De_Cristoforis

24. Walk 8. Hamburg Passages. https://evgeniaczech.tourister.ru/photoalbum/26212

25. La ville de Lyon https://www.lesbateauxlyonnais.com/la-ville-de-lyon-de

26. Traboule https://it.wikipedia.org/wiki/Traboule -

27. Venice https://de.wikipedia.org/wiki/Venedig

28. Traboule https://it.wikipedia.org/wiki/Traboule-

29. Walking in Paris. What passage... https://wokrug-sveta.livejournal.com/27955.html

30. N. N. Shesterneva Architectural typology and principles of development of the existing pedestrian communications of the largest city: the example of St. Petersburg. Diss. Cand. Arch. (SPB, SPbGASU, 2007)

31. About the St. Petersburg strategy for the preservation of cultural heritage. Resolution of the Government of St. Petersburg of November 1, 2005 N 1681

32. The concept of pedestrian spaces and continuous pedestrian routes. Committee for Urban Planning and Architecture of St. Petersburg. http://kgainfo.spb.ru/docs/2017/eshehod_prostranstvo.pdf

33. E.G. Yasin Political economy of housing reform

34. http://ru-90.ru/content/\%D1\%8F\%D1\%81\%D0\%B8\%D0\%BD-\%D0\%B5\%D0\%B3$\% \mathrm{D} 0 \% \mathrm{BF} \% \mathrm{D} 0 \% \mathrm{BE} \% \mathrm{D} 0 \% \mathrm{BB} \% \mathrm{D} 0 \% \mathrm{~B} 8 \% \mathrm{D} 1 \% 82 \% \mathrm{D} 1 \% 8 \mathrm{D} \% \mathrm{D} 0 \% \mathrm{BA} \% \mathrm{D} 0 \% \mathrm{BE} \% \mathrm{D} 0$ $\% \mathrm{BD} \% \mathrm{D} 0 \% \mathrm{BE} \% \mathrm{D} 0 \% \mathrm{BC} \% \mathrm{D} 0 \% \mathrm{~B} 8 \% \mathrm{D} 1 \% 8 \mathrm{~F}-$ $\% \mathrm{D} 1 \% 80 \% \mathrm{D} 0 \% \mathrm{~B} 5 \% \mathrm{D} 1 \% 84 \% \mathrm{D} 0 \% \mathrm{BE} \% \mathrm{D} 1 \% 80 \% \mathrm{D} 0 \% \mathrm{BC} \% \mathrm{D} 1 \% 8 \mathrm{~B}-$ $\% \mathrm{D} 0 \% \mathrm{~B} 6 \% \mathrm{D} 0 \% \mathrm{BA} \% \mathrm{D} 1 \% 85$ (reference date: 10.09 .2017 )

35. Tax Code of the Russian Federation. http://www.consultant.ru/document/cons_doc_LAW_19671/

36. A "courtyard" easement is proposed to be introduced in St. Petersburg. https://www.pnp.ru/social/v-peterburge-khotyat-vvesti-dvorovyy-servitut.html

37. In a sideway. Legislative Assembly of Saint Petersburg intends to open private access yards for public access. https://www.dp.ru/a/2019/06/23/Okolnim_putem

38. Experts: Petersburg's outbuildings will have to be discussed at the federal level. http://kanoner.com/2013/04/15/107988/ 